Magazine of Concrete Research Volume 63 Issue 9

Concrete cover cracking caused by steel reinforcement corrosion

Al-Harthy, Stewart and Mullard
Magazine of Concrete Research, 2011, 63(9), 655-667 doi: 10.1680/macr.2011.63.9.655 Paper 900080 Received 30/05/2009; revised 31/07/2010; accepted 10/08/2010 Thomas Telford Ltd ๑ 2011
,

\title{
Concrete cover cracking caused by steel reinforcement corrosion
}

Ali S. Al-Harthy

Associate Professor, Dean of Engineering, Department of Civil \&

Architectural Engineering, Sultan Qaboos University, Al-Khaudh, Oman

Mark G. Stewart

Professor, Director of Centre for Infrastructure Performance and
Reliability, School of Engineering, The University of Newcastle, Callaghan, NSW, Australia

John Mullard

Engineer, Robert Bird Group, Newcastle, NSW, Australia

The paper reviews previously reported predictive models on corrosion-induced crack initiation and propagation and presents new additional results of ongoing accelerated corrosion tests conducted at The University of Newcastle. In addition to eight concrete specimens previously tested, six new specimens were tested to study the effect of reinforcement confinement, concrete strength (24 and $8 \mathrm{MPa}$ ), cover (10 and $20 \mathrm{~mm}$ ) and reinforcing bar diameter (16 and $27 \mathrm{~mm}$ ) on corrosion-induced cracking. Time-dependent crack widths were measured for different reinforced concrete slabs for corrosion rates up to $169 \mu \mathrm{A} / \mathrm{cm}^{2}$. It was found that predictions of time to crack initiation are highly scattered and can differ by as much as two orders of magnitude. It was also found that crack initiation and propagation times increase with increasing cover and decrease with increasing reinforcing bar diameter and

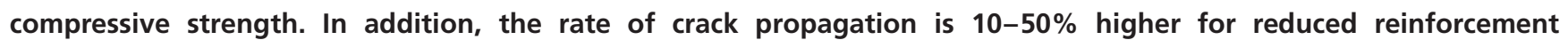
confinement such as at the edge of a slab or corner of a column. The experimental results are compared with existing crack initiation and propagation predictive models allowing for the accuracy of existing models to be assessed and showing potential areas for further research.

\section{Introduction}

Deterioration of reinforced concrete (RC) structures caused by the corrosion of the reinforcing steel is a major concern in the design, construction and maintenance of RC structures. In many parts of the world, damage caused by carbonation and chlorideinduced corrosion to bridges, piers, parking garages, coastal structures, etc. is the greatest threat to the durability and service life of concrete structures. For example, Koch et al. (2002) indicated that the annual direct cost of corrosion to bridges in the USA is $\$ 5 \cdot 9-9 \cdot 7$ billion.

Corrosion cracking in concrete is unsightly but, more importantly, may accelerate the corrosion process and lead to reduced structural capacity. Excessive cracking is considered an important and costly mode of failure for the estimation of life-cycle costs and optimisation of repair and maintenance strategies for corroded RC structures (Stewart, 2006; Stewart and Val, 2003). The definition of 'excessive' cracking depends on individual conditions and asset owners' policies. A limit crack width of $0 \cdot 3-0 \cdot 4 \mathrm{~mm}$ may be appropriate for a durability limit state (ACI, 1978). A limit crack width of $1.0 \mathrm{~mm}$ is specified for the limit state with respect to spalling (Duracrete, 2000). However, this limit is empirical and does not represent an event where the concrete cover is lost. These limits are valid for both longitudinal and transverse cracks. Longitudinal cracks along steel reinforcements are an indication of deterioration due to corrosion and transverse cracks in beams are normally caused by flexure
However, large flexural cracks such as the limits of 0.3 and $0.4 \mathrm{~mm}$ may lead to further corrosion of the steel.

A number of studies have been carried out on the cracking of concrete due to reinforcement corrosion during the last three decades (Alonso et al., 1998; Andrade et al., 1993; Austroads, 2004; Bazant, 1979; Bhargava et al., 2005; Liang et al., 2002; Liu and Weyers, 1998; Morinaga, 1989; Rodriguez et al., 1996; Vu et al., 2005; Webster and Clark, 2000). The models and results developed from these studies differ, mainly due to different experimental methods, parameters used and modelling assumptions made by the different researchers. Many of the developed models are empirically based from experimental data, but some are derived from mechanics-based approaches. Therefore, a comparison of analytical model predictions for realistic structural configurations and scenarios is useful when assessing their applicability to service life predictions of RC structures.

This paper critically reviews predictive models for crack initiation and propagation in concrete due to corrosion of the reinforcing bars. A more detailed description of the predictive models can be found elsewhere (Al-Harthy and Stewart, 2006). A key interest for researchers and asset owners is predicting the time to first repair and optimising maintenance strategies by minimising lifecycle costs. Stochastic methods are often used for these purposes (Frangopol et al., 1997; Mullard and Stewart, 2009; Stewart, 2006; Vu and Stewart, 2000). Since crack initiation and propaga- 
tion models are to be used in such stochastic analyses, the computational effort in calculating crack initiation and propagation should thus be minimised. Crack modelling using numerical methods such as finite-element methods or finite-difference methods (Molina et al., 1993; Pantazopoulou and Papoulia, 2001) is more reliable. However, because such numerical methods often result in excessive computational times, they are not considered in this review.

This paper also describes accelerated corrosion tests on six RC specimens to study the effect of concrete cover, reinforcing bar diameter and concrete compressive strength on corrosion-induced crack initiation and propagation. The experiments are an extension of previous corrosion studies (Vu et al., 2005) carried out at The University of Newcastle. The effect of confinement of the reinforcing bars on corrosion-induced crack initiation and propagation is also reported. The results are compared with existing predictive models.

\section{Research significance}

In order to accurately predict times to maintenance and repair of RC structures, information on when severe corrosion-induced cracking occurs is required. The accelerated corrosion tests of RC slabs conducted in this study provide new data that will help improve corrosion-induced crack initiation and propagation models. In particular, a novel aspect of the experimental programme is data showing the effect of confinement of reinforcing bars on cracking phenomena. These results show that rates of crack propagation are about $10-50 \%$ higher for reduced reinforcement confinement such as at the edge of a slab or corner of a column.

\section{Comparison of predictions from crack initiation and propagation models}

Corrosion due to chlorides in concrete is known to cause mainly pitting corrosion; corrosion due to carbonation of concrete results in general corrosion or uniform corrosion of the reinforcing steel. In the experiments carried out in this study and other studies using impressed current methods to accelerate corrosion ( $\mathrm{Vu}$ et al., 2005), loss of metal due to corrosion was more uniform along the length of the bar. However, several signs of pitting corrosion were observed on the bar surfaces. In the slabs tested in this study, the mean maximum pit depth reached up to six times the depth calculated from general corrosion $\left(x_{\text {avg }}=0 \cdot 0116 i_{\text {corr }} T\right)$ where $i_{\text {corr }}$ is the corrosion rate $\left(\mu \mathrm{A} / \mathrm{cm}^{2}\right)$ and $T$ is time in years since corrosion initiation. The appearance of localised corrosion (pitting) along the length of the reinforcing bars did not prevent crack initiation and propagation occurring simultaneously along the length and parallel to the reinforcing bars. Cracks started initially as a few narrow short cracks along the reinforcements. The number and width of these cracks increased as testing progressed, eventually joining to form one crack along the reinforcement. Unfortunately, it was not possible in the test set-up to correlate cracking pattern with type of corrosion (local versus general) as this was not the main objective of this study. However, the results of an experimental study of two beams exposed to a chloride environment for 14 years and 23 years (Zhang et al., 2010) indicate that, at the cracking initiation stage and the first stage of crack propagation, localised corrosion due to chloride ingress is the predominant corrosion pattern and pitting corrosion is the main factor that influences the cracking pattern. As corrosion cracking increases, general corrosion develops rapidly and gradually becomes predominant in the second stage of cracking propagation. Torres-Acosta et al. (2004) studied accelerated corrosion with impressed current and found that more corrosion was needed for a localised corrosion process than for general corrosion processes to generate similar crack widths. Further in-depth comparisons of crack morphology between generalised and localised corrosion are therefore needed in future tests where impressed current is used to accelerate corrosion.

\section{Crack initiation}

Table 1 shows a summary of some previous crack initiation studies. Al-Harthy and Stewart (2006) compared crack initiation model predictions for concrete members having different covers $(25,50$ and $75 \mathrm{~mm})$, bar diameters $(16$ and $27 \mathrm{~mm})$ and concrete strengths (20 and $43 \mathrm{MPa}$ ). These structural configurations were chosen to allow comparison of prediction models with crack initiation experimental data reported in another similar study $(\mathrm{Vu}$ et al., 2005). Crack initiation is defined here as a crack width of $0.05 \mathrm{~mm}$, which is barely visible to the human eye. Figure 1 shows a comparison of times to crack initiation obtained from existing predictive models (Alonso et al., 1998; Andrade et al., 1993; Austroads, 2004; Bazant, 1979; Liang et al., 2002; Liu and Weyers, 1998; Morinaga, 1989; Rodriguez et al., 1996; Webster and Clark, 2000) for cover/diameter $(C / d)$ ratios of 25/16, 50/27 and $50 / 16(1.56,1.85$ and $3 \cdot 13)$, a concrete compressive strength $\left(f_{\mathrm{c}}^{\prime}\right)$ of $43 \mathrm{MPa}$ and corrosion rate $\left(i_{\text {corr }}\right)$ of $100 \mu \mathrm{A} / \mathrm{cm}^{2}$ where the surface area represents the surface area of steel. Experimental crack initiation data reported by $\mathrm{Vu}$ et al. (2005) is also shown in Figure 1. The difference between model predictions for time to crack initiation $\left(t_{1 \mathrm{st}}\right)$ and the experimental data ranges from -97 to $+203 \%$; most model predictions are within -50 and $+78 \%$ of the experimental data. All the models and observations show an increase in $t_{1 \mathrm{st}}$ with increasing $C / d$. The model of Webster and Clark (2000) does not take into account the effect of bar diameter, and therefore no change in $t_{1 \text { st }}$ occurs when the bar diameter is changed. Figure 1 shows that the model of Liu and Weyers (1998) predicts a decrease in $t_{1 \mathrm{st}}$ when the bar diameter is decreased from $27 \mathrm{~mm}(C / d=1.85)$ to $16 \mathrm{~mm}(C / d=3 \cdot 13)$ while cover is constant $(C=50 \mathrm{~mm})$. This also applies to the studies of Bazant (1979), Liang et al. (2002) and Morinaga (1989). However, this is contrary to observations made by others (Alonso et al., 1998; Austroads, 2004; Rasheeduzzafar et al., 1992; Rodriguez et al., 1996) where a larger diameter reinforcing bar leads to earlier crack initiation. The role of cover or diameter in crack initiation is not taken into account in the model of Andrade et al. (1993).

Moderate to high corrosion activity in $\mathrm{RC}$ is categorised as having corrosion rates of $0.5-1 \cdot 0 \mu \mathrm{A} / \mathrm{cm}^{2}$ (Brite-EuRam, 1995). Using the more realistic corrosion rate of $1 \mu \mathrm{A} / \mathrm{cm}^{2}$, Figure 2 


\begin{tabular}{|c|c|c|c|c|}
\hline Study & Type & Specimen type & Main variables & Comments \\
\hline Bazant (1979) & $\begin{array}{l}\text { Analytical } \\
\text { (mechanics-based) }\end{array}$ & & $\begin{array}{l}\text { Corrosion rate, bar } \\
\text { diameter, cover, bar } \\
\text { spacing, concrete } \\
\text { properties }\end{array}$ & $\begin{array}{l}\text { Not validated } \\
\text { experimentally. } \\
\text { Underestimates time to } \\
\text { corrosion }\end{array}$ \\
\hline Liu and Weyers (1998) & $\begin{array}{l}\text { Analytical } \\
\text { (mechanics-based) }\end{array}$ & & $\begin{array}{l}\text { Corrosion rate, critical } \\
\text { weight of rust products }\end{array}$ & $\begin{array}{l}\text { Model correlated from } \\
\text { small number of } \\
\text { accelerated corroded } \\
\text { slabs }\end{array}$ \\
\hline Liang et al. (2002) & $\begin{array}{l}\text { Analytical } \\
\text { (mechanics-based) }\end{array}$ & & Same as Bazant's model & $\begin{array}{l}\text { Modification of Bazant's } \\
1979 \text { study to match } \\
\text { observed corrosion in } \\
\text { only one bridge }\end{array}$ \\
\hline Rodriguez et al. (1996) & Empirical & $\begin{array}{l}\text { Singly reinforced prisms. } \\
\text { Corrosion accelerated } \\
\text { with impressed current }\end{array}$ & $\begin{array}{l}\text { Corrosion rate, cover to } \\
\text { reinforcement diameter } \\
\text { ratio, splitting strength } \\
\text { of concrete }\end{array}$ & \\
\hline Webster and Clark (2000) & Empirical & $\begin{array}{l}\text { Data from available } \\
\text { experimental results }\end{array}$ & Corrosion rate, cover & $\begin{array}{l}\text { Effect of bar diameter } \\
\text { not considered }\end{array}$ \\
\hline Andrade et al. (1993) & Empirical & $\begin{array}{l}\text { Singly reinforced prisms. } \\
\text { Corrosion accelerated } \\
\text { with impressed current }\end{array}$ & Corrosion rate & $\begin{array}{l}\text { Very limited. Cover and } \\
\text { bar diameter not } \\
\text { considered }\end{array}$ \\
\hline Morinaga (1989) & Empirical & $\begin{array}{l}\text { Singly reinforced } \\
\text { cylinders. Corrosion } \\
\text { accelerated with } \\
\text { impressed current }\end{array}$ & $\begin{array}{l}\text { Corrosion rate, bar } \\
\text { diameter, cover to } \\
\text { reinforcement diameter } \\
\text { ratio }\end{array}$ & $\begin{array}{l}\text { Time prediction shorter } \\
\text { than observed one }\end{array}$ \\
\hline Alonso et al. (1998) & Empirical & $\begin{array}{l}\text { Singly reinforced prisms. } \\
\text { Corrosion accelerated } \\
\text { with impressed current }\end{array}$ & $\begin{array}{l}\text { Corrosion rate, cover to } \\
\text { reinforcement diameter } \\
\text { ratio }\end{array}$ & \\
\hline Austroads (2004) & Empirical & $\begin{array}{l}\text { Slabs with multiple bars. } \\
\text { Corrosion accelerated } \\
\text { with high chlorides }\end{array}$ & $\begin{array}{l}\text { Model based on Liu and } \\
\text { Weyers (1998) model }\end{array}$ & \\
\hline
\end{tabular}

Table 1. Summary of some previous crack initiation studies

shows the relative increase in time to crack initiation when the concrete cover is increased from 25 to $75 \mathrm{~mm}$. As can be seen, increasing the cover will increase the time to crack initiation. For example, increasing the cover from 25 to $75 \mathrm{~mm}$ increases $t_{1 \mathrm{st}}$ by as much as $550 \%$ as in the Austroads (2004) model or by as little as $55 \%$ as in the model of Rodriguez et al. (1996). For the same increase in cover, the average increase in $t_{1 \mathrm{st}}$ for all the prediction models is $200 \%$.

Figure 3 shows the relative increase in $t_{1 \mathrm{st}}$ when the reinforcing bar diameter increases from 16 to $27 \mathrm{~mm}$. The models show the contradictory effect of reinforcing bar diameter. Some models (Bazant, 1979; Liang et al., 2002; Liu and Weyers, 1998; Morinaga, 1989) predict an increase in $t_{1 \mathrm{st}}$ as reinforcing bar diameter increases, and the average increase predicted by these models is $75 \%$. However, other models (Alonso et al., 1998; Austroads, 2004; Rodriguez et al., 1996) predict a decrease in $t_{1 \mathrm{st}}$ when larger diameter bars are used. The average predicted decrease in $t_{1 \text { st }}$ from these models is $20 \%$ for a reinforcing bar diameter increase from 16 to $27 \mathrm{~mm}$.

Figure 4 shows the effect of a change in concrete compressive strength on $t_{1 \mathrm{st}}$ for constant $C=25 \mathrm{~mm}, d=16 \mathrm{~mm}$ and $i_{\text {corr }}=100 \mu \mathrm{A} / \mathrm{cm}^{2}$. Only the model of Rodriguez et al. (1996) shows a decrease in $t_{1 \mathrm{st}}$ with increasing compressive strength; for example, $t_{1 \text { st }}$ decreased by $47 \%$ when concrete compressive strength is increased from 20 to $43 \mathrm{MPa}$. This phenomenon will be discussed in more detail later in this paper. It should also be noted that, although every effort has been made to ensure that the input parameters are within the limits of the models, this may not always be the case, particularly for empirically developed models where limits of applicability were not explicitly stated by the authors.

The mathematical model of Bazant (1979) has not been validated experimentally. The estimated time to cracking given by the 


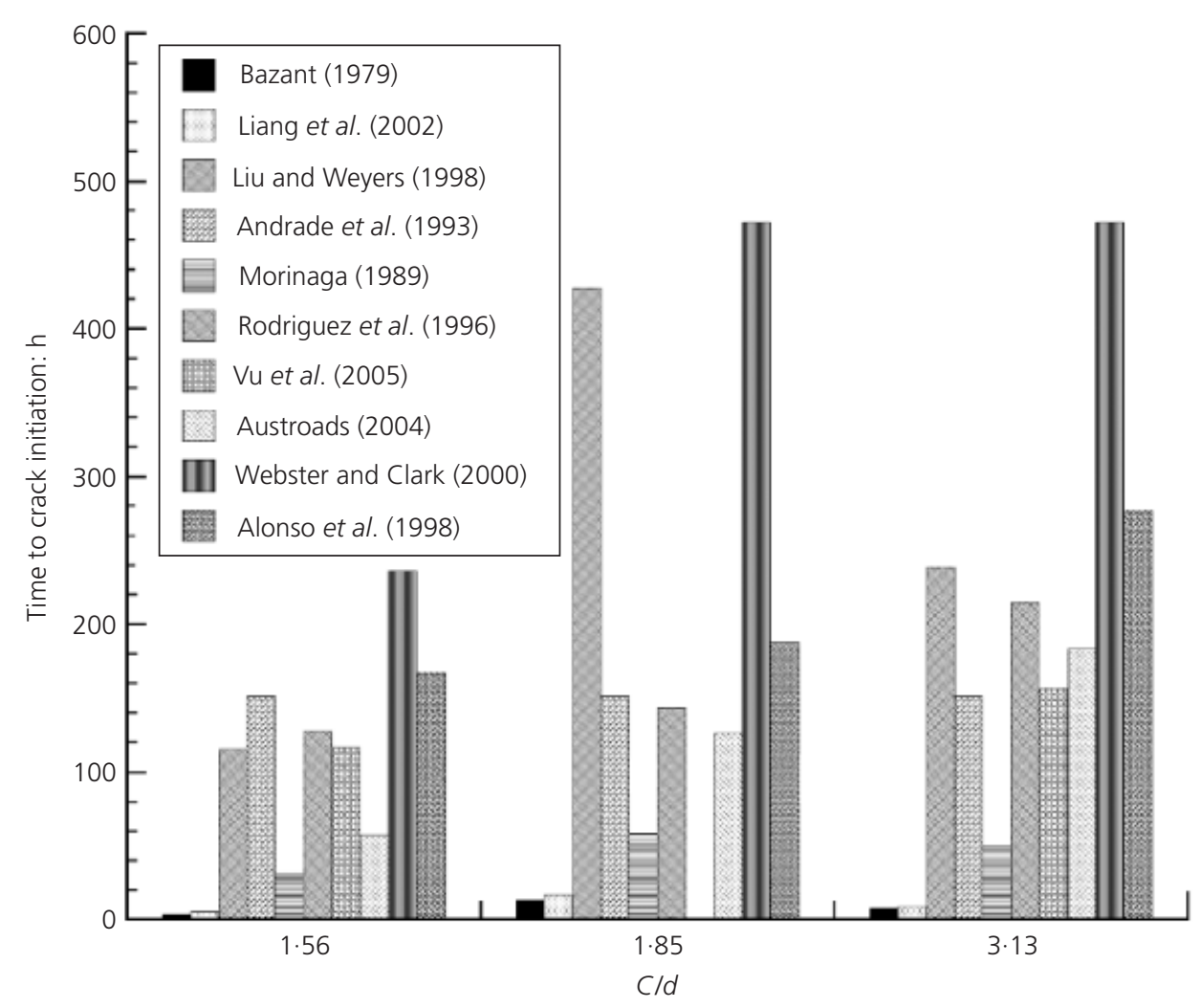

Figure 1. Prediction of time to crack initiation for $f_{c}^{\prime}=43 \mathrm{MPa}$ and $i_{\text {corr }}=100 \mu \mathrm{A} / \mathrm{cm}^{2}$

model is significantly shorter than that observed in field or laboratory work. The Morinaga model is based on accelerated corrosion tests carried out on singly reinforced and hollow concrete cylinders (Morinaga, 1989). This model also gives $t_{1 \mathrm{st}}$ values lower than those observed experimentally. The Liang model (Liang et al., 2002) is a modification of the model of Bazant (1979) to more closely match observations of a 69-yearold bridge in Taipei. It was found (Al-Harthy and Stewart, 2006) that the modification proposed by Liang et al. (2002) results in a 15 to $30 \%$ increase in $t_{1 \mathrm{st}}$ when compared with Bazant's results. As the Bazant model predicts much lower values for $t_{1 \mathrm{st}}$, the model proposed by Liang et al. (2002) does not seem to be a significant improvement. Although the analytical model proposed by Liu and Weyers (1998) has the advantage of incorporating the theory of rate of rust production with time, its limitation is that it was validated with only a very small number of experiments. For instance, out of 40 slab specimens, only three slab series (10 specimens) containing the same size reinforcing bars but having different covers and chloride contents were reported in their paper within the first 5 years of outside exposure. Moreover, Chernin and Val (2008) suggest that the derivation of a key parameter $\left(k_{\mathrm{p}}\right)$, which is related to metal loss, in the Liu and Weyers model is incorrect and not solvable.

From observations and common trends among the models and experimental results, it can be concluded that (a) the time to crack initiation $t_{1 \mathrm{st}}$ increases with increase in cover $C$

(b) $t_{1 \mathrm{st}}$ increases with increase in cover to diameter ratio $(\mathrm{C} / \mathrm{d})$ when both $C$ and $d$ increase

(c) there are contradictory predictions by some models of $t_{1 \mathrm{st}}$ due to increasing reinforcing steel diameter and tensile strength of concrete (or decreasing porosity).

\section{Crack propagation}

Very few analytical crack propagation models were found in the literature. The models found considered the effect of cover $C$, reinforcing bar diameter $d$, water/cement (w/c) ratio and corrosion rate $i_{\text {corr }}$ on crack propagation. The crack propagation time since crack initiation $t_{\text {ser }}$ is calculated as

1. $t_{\mathrm{ser}}=t_{\mathrm{sp}}-t_{1 \mathrm{st}}$

where $t_{\mathrm{sp}}$ is crack propagation time measured from the start of the experiment or age of the structure.

In order to minimise the error in predicting the time to cracking when extrapolating accelerated corrosion test results to the behaviour of real RC structures, Vu et al. (2005) proposed a rate of loading correction factor $k_{\mathrm{R}}$. It is assumed that the real time to crack propagation is proportional to the ratio of the experimental 


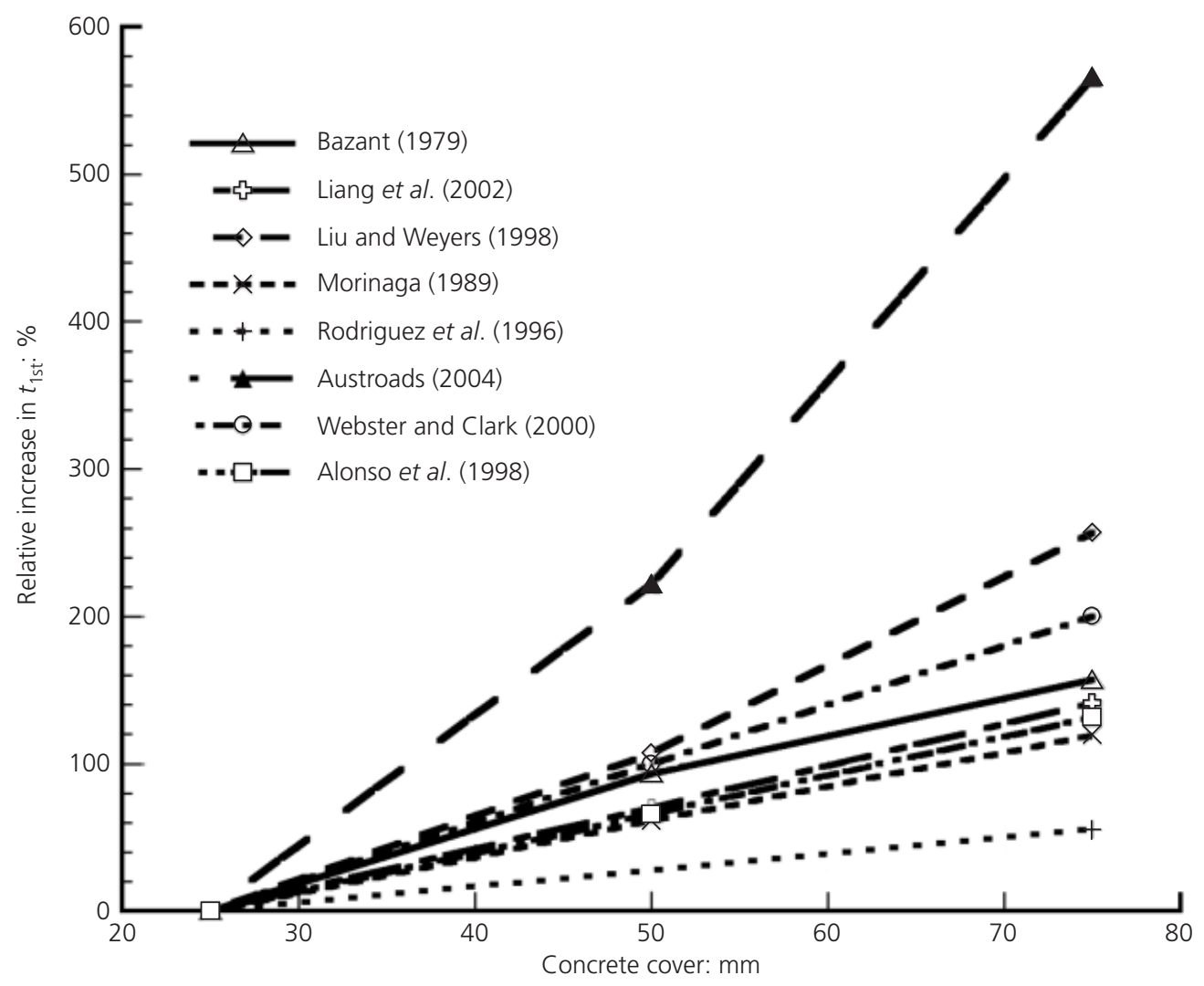

Figure 2. Effect of concrete cover on model predictions of time to crack initiation $\left(d=16 \mathrm{~mm} ; i_{\text {corr }}=1 \mu \mathrm{A} / \mathrm{cm}^{2}\right)$

accelerated corrosion rate and the real corrosion rate. A rate of loading correction factor $k_{\mathrm{R}}$ is then applied such that the time to crack propagation for real RC structures $t_{\mathrm{cr}(\text { real })}$ with any value of corrosion rate $i_{\text {corr(real) }}$ is

2. $\quad t_{\text {cr(real })}=k_{\mathrm{R}} \frac{i_{\text {corr( }(\exp )}}{i_{\text {corr(real })}} t_{\text {cr(exp) }}$

where $i_{\text {corr(exp) }}$ is the accelerated corrosion rate and $t_{\operatorname{cr}(\exp )}$ is the observed time to cracking obtained from accelerated corrosion tests.

The line of best fit to limited available data when $i_{\text {corr(exp) }} \leqslant 200 \mu \mathrm{A} / \mathrm{cm}^{2}$ yielded

3. $k_{\mathrm{R}} \approx 0.95\left[\exp \left(-\frac{0 \cdot 3 i_{\text {corr }(\exp )}}{i_{\text {corr(real })}}\right)-\frac{i_{\text {corr }(\exp )}}{2500 i_{\text {corr(real })}}+0 \cdot 3\right]$

To extrapolate the data of $\mathrm{Vu}$ et al. (2005) where $i_{\text {corr(exp) }}=100 \mu \mathrm{A} / \mathrm{cm}^{2}$ to a real corrosion rate of $1 \mu \mathrm{A} / \mathrm{cm}^{2}, k_{\mathrm{R}}$ is approximately equal to $0 \cdot 25$. All previous work simply assumes that $k_{\mathrm{R}}=1$ (linear function of corrosion rate), which has been shown by $\mathrm{Vu}$ et al. (2005) to be incorrect. $\mathrm{Vu}$ et al. (2005) reviewed crack propagation data and found that cracks may propagate more slowly as the corrosion rate increases when $i_{\text {corr(exp) }}$ is less than $200 \mu \mathrm{A} / \mathrm{cm}^{2}\left(k_{\mathrm{R}}<1\right)$, but may propagate more quickly as corrosion rate increases for corrosion rates above $200 \mu \mathrm{A} / \mathrm{cm}^{2}\left(\mathrm{k}_{\mathrm{R}}>1\right)$.

Vidal et al. (2004) measured corrosion crack widths and mass loss in the steel reinforcements in two beams that had naturally corroded in a saline environment and were subjected to wetting-drying cycles over periods of 14 and 17 years. As the authors did not report an estimate of the corrosion rate, a corrosion rate of $1.4 \mu \mathrm{A} / \mathrm{cm}^{2}$ was inferred from corrosion penetration data (beam A). Using this corrosion rate in Equation 3 yields $k_{\mathrm{R}}=0.91$. A more elaborate estimate assuming a pit factor of 6 will only result in a small change, $k_{\mathrm{R}}=1 \cdot 1$. In order to illustrate the importance of the loading correction factor and how it can be used to extrapolate data from laboratory corrosion tests to real corrosion rates, Figure 5 shows a comparison between crack propagation model predictions (Andrade et al., 1993; Duracrete, 1998; Vidal et al., 2004; Vu et al., 2005) for $C=50 \mathrm{~mm}, d=16 \mathrm{~mm}$ (top cast reinforcing bars) and $i_{\text {corr }}=1 \mu \mathrm{A} / \mathrm{cm}^{2}$. The predictions of crack propagation times from the model of Andrade et al. (1993) are the highest. However, because the effect of cover, bar diameter and concrete strength are not considered, the accuracy of this 


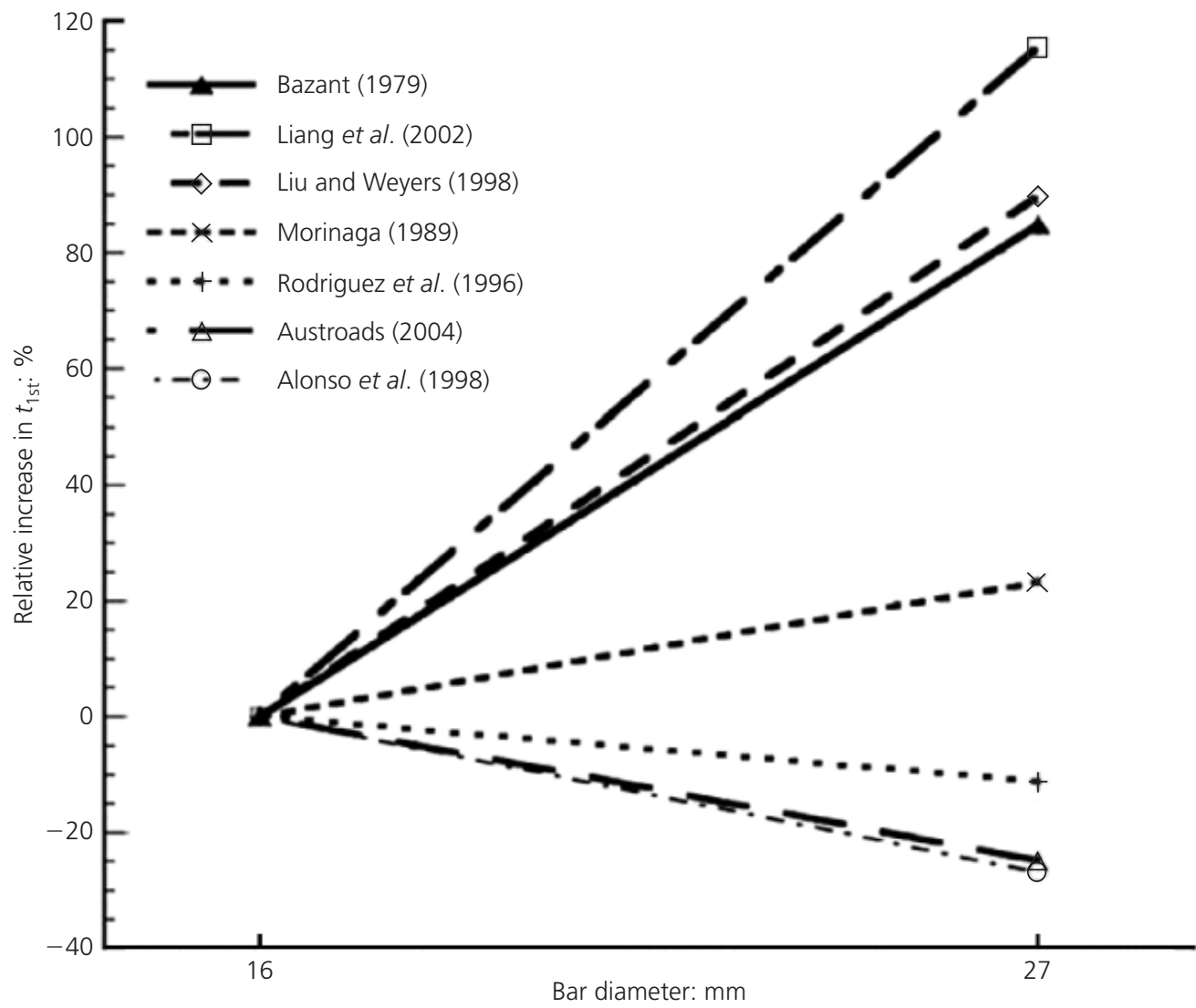

Figure 3. Effect of bar diameter on model predictions of time to crack initiation $\left(i_{\text {corr }}=1 \mu \mathrm{A} / \mathrm{cm}^{2}\right)$

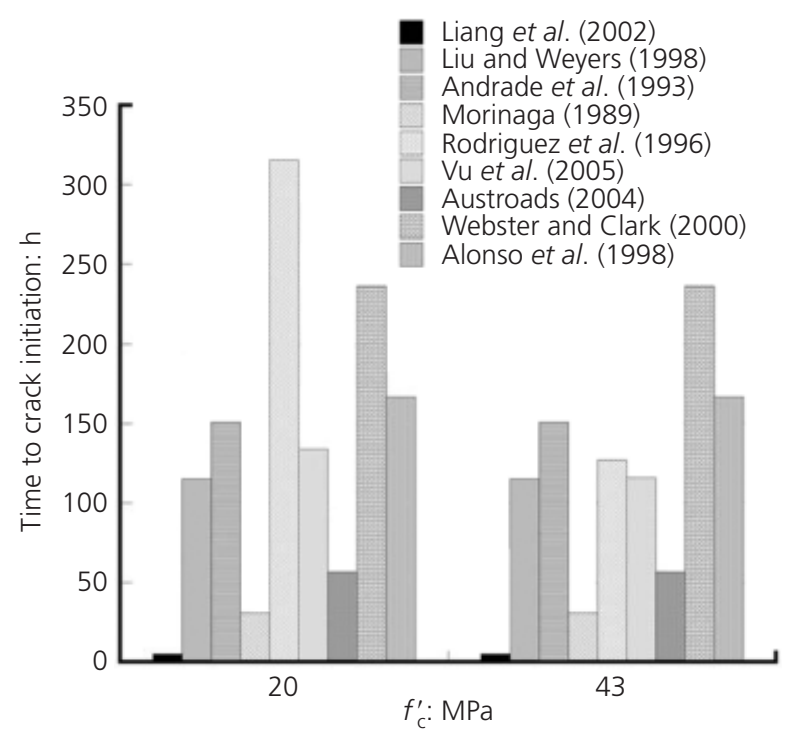

Figure 4. Effect of concrete compressive strength on prediction of time to crack initiation, $C=25 \mathrm{~mm}$; $i_{\text {corr }}=100 \mu \mathrm{A} / \mathrm{cm}^{2}$ model is doubtful. As Figure 5 shows, Vidal et al.'s gives the longest times for crack propagation. $\mathrm{Vu}$ et al.'s model predictions are the lowest, mainly due to the effect of a low $k_{\mathrm{R}}$ value $\left(k_{\mathrm{R}}=0 \cdot 25\right)$. On average, the prediction times from the models of Duracrete (1998) and Vidal et al. (2004) are respectively about 1.3 and 4.4 times the predictions of the Vu et al. (2005) model. Figure 5 also shows a significant reduction in crack propagation time for the Vidal et al. (2004) model when the reinforcing bar diameter is increased to $d=27 \mathrm{~mm}$. Cover, reinforcing bar diameter and w/c ratio do not affect crack propagation times for the Duracrete (1998) model. These parameters (except reinforcing bar diameter) also do not affect crack propagation in the Vidal et al. (2004) model.

The beams studied by Vidal et al. (2004) had very wide longitudinal cracks along almost the full length of the beams. The crack widths ranged from 0.4 to $1.8 \mathrm{~mm}$, with most at the higher end of this range. The corrosion that took place is considered as pitting corrosion, but uniform corrosion will be assumed for comparison purposes with the $\mathrm{Vu}$ et al. (2005) model. 


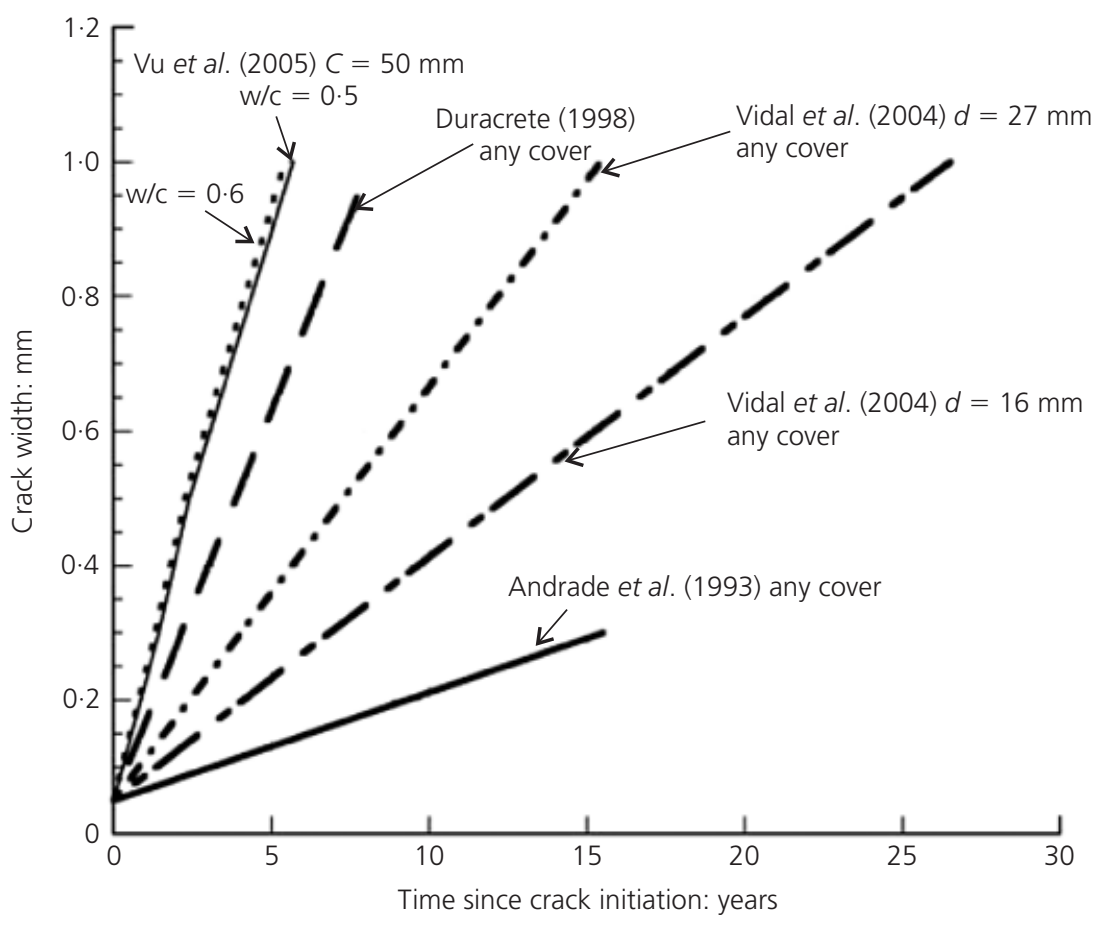

Figure 5. Comparison of predictions from crack propagation

models $\left(i_{\text {corr }}=1 \mu \mathrm{A} / \mathrm{cm}^{2}\right)$

Alonso et al. (1998) pointed out that the presence of stirrups does not influence the time to crack initiation or propagation. A concrete member with corroded transverse reinforcing steel such as stirrups will show signs of corrosion cracks earlier (due to a smaller cover) than a member with no transverse reinforcements. The effect of corroded stirrups will be on the bond strength of the members. There seems to be no effect of stirrups on corrosion crack propagation in the study of Vidal et al. (2004).

The large scatter in model predictions of time to crack initiation and propagation is due to different experimental procedures and environments used in the laboratory and field testing and also to different assumptions and parameters used when deriving the analytical models. Additionally, the specimens studied in many of the experiments were of different sizes and were often reinforced with only a single reinforcing bar. Only a few experiments (Austroads, 2004; Liu and Weyers, 1998; Vu et al., 2005) were carried out with concrete specimens containing more than one reinforcing bar. This is an important difference as the degree of confinement of the reinforcing bars (such as the volume of the surrounding concrete and the spacing between reinforcing bars) will be shown later in this paper to have a significant effect on crack initiation and propagation. If there is a row of parallel bars that all corrode simultaneously, the expansion of an interior bar (e.g. bar 2 in Figure 6(b)) caused by the corrosion products may be restricted by expansion of the two adjacent reinforcing bars (bars 1 and 3). This confinement effect will allow for reduced expansions and cracking in speci-

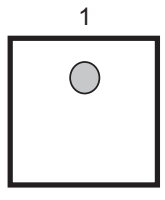

(a)

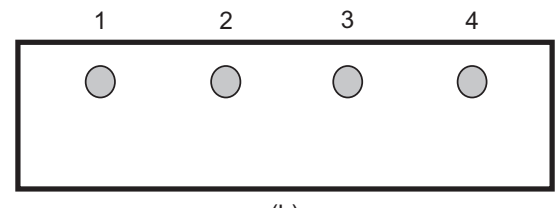

(b)
Figure 6. Effect of reinforcement confinement

mens when compared with specimens containing only a single reinforcing bar (Figure 6(a)).

As the Duracrete (1998) model was developed from singly reinforced specimens, the inclusion of confinement effects would reduce crack propagation for interior bars, hence increasing the difference between that and the model of $\mathrm{Vu}$ et al. (2005). Assuming that the Vidal et al. (2004) model accurately reproduces the crack width data of the two naturally corroded beams over periods of 14 and 17 years, the predictions of the $\mathrm{Vu}$ et al. (2005) and Duracrete (1998) models both seem to be quite conservative.

Another reason for the large differences between the predictive models is that corrosion is strongly dependent on environmental factors (temperature, relative humidity) and properties of the concrete structure. These factors act simultaneously on the corrosion process in in-service conditions and their influence on the corrosion process should be considered as an interaction 
among them. Due to a lack of long-term corrosion data from the field, the interaction model for corrosion has not been sufficiently studied. Most of the research work concerning accelerated corrosion tests is limited to the effects of an individual variable. More data are thus needed to better assess the accuracy of the predictive models reviewed in this paper.

\section{Experimental investigation}

Six RC specimens $(550 \times 1000 \mathrm{~mm}$ rectangular slabs of thickness $250 \mathrm{~mm}$ ) were constructed. The top mat of the slab contained four mild steel reinforcing bars spaced $150 \mathrm{~mm}$ apart (see Figure 6(b)). The impressed current method was used to accelerate the corrosion process (Figure 7). This involves placing the soffit of an $\mathrm{RC}$ specimen in an $\mathrm{NaCl}$ solution and applying a constant electrical current to the reinforcing bars. A current regulator keeps the current constant over time. The steel bar acts as the anode, the stainless steel plate submerged in the $\mathrm{NaCl}$ solution acts as the cathode and the pore fluid in the concrete is the electrolyte.

With the impressed current method, corrosion rates ranging from 10 to $20000 \mu \mathrm{A} / \mathrm{cm}^{2}$ can be achieved by adjusting the level of impressed current in a reinforcing steel bar (Andrade et al., 1993; Pantazopoulou and Papoulia, 2001; Rodriguez et al., 1996). This gives the impressed current method a distinct advantage over other accelerated corrosion testing methods. In addition to considerable savings in time, the ability to control the rate of corrosion allows for more accurate and reproducible test design. $\mathrm{X}$-ray diffraction measurements of steel bars corroded by an impressed current of $100 \mu \mathrm{A} / \mathrm{cm}^{2}$ showed that the chemical composition and morphology of the corrosion products is similar to the rust observed in specimens exposed long term to a marine environment ( $\mathrm{Vu}, 2003)$. Care and Raharinaivo (2007) showed similarities between accelerated corrosion and natural corrosion and, using energy dispersive spectrometry coupled with scanning

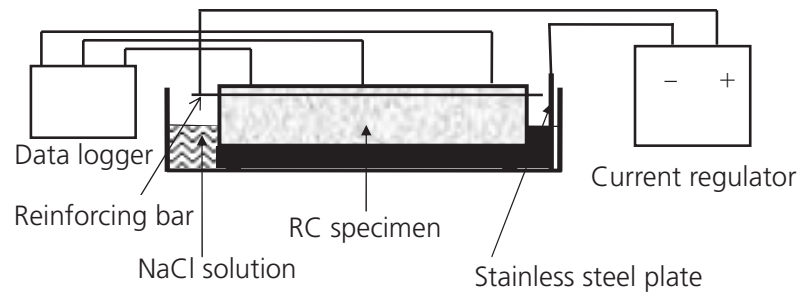

Figure 7. Test set-up electron microscopy, also showed that corrosion products formed in samples under accelerated corrosion with impressed current are similar to products formed in samples corroded in a natural environment. Accelerated corrosion tests using impressed current techniques may not fully simulate the corrosion process, but evidence to date does not suggest such techniques using relatively modest accelerated corrosion rates (up to $200 \mu \mathrm{A} / \mathrm{cm}^{2}$ ) are not valid for crack initiation and propagation studies.

Ordinary Portland cement concrete was supplied by a local readymixed concrete plant. Table 2 shows the mix constituents. The calculated w/c ratios from batch quantities were 0.47 and 0.74 for series III and IV, respectively. An air-entraining agent and waterreducing admixture were also used by the ready-mix plant. Standard test cylinders (100 $\mathrm{mm}$ diameter, $200 \mathrm{~mm}$ length) were tested at 28 days to determine concrete compressive $\left(f_{\mathrm{c}}^{\prime}\right)$ and tensile (splitting) strengths $\left(f_{\text {t,cyl }}\right)$ (Table 3$)$. The cylinder specimens were moist-cured for 28 days before testing. The steel reinforcing bars used in this study were round mild steel bars rather than ribbed high-yield steel in order to be consistent with the reinforcement type used in a similar previous study ( $\mathrm{Vu}$ et al., 2005). Calcium chloride (3\% by weight of cement) was added to the mix to induce corrosion along the length of the reinforcing bars.

To generate cracks within a reasonable time period, accelerated corrosion rates of 59,100 and $169 \mu \mathrm{A} / \mathrm{cm}^{2}$ were used. The following variables were used in this study: cover $C=10$ and $20 \mathrm{~mm}$; bar diameter $d=16$ and $27 \mathrm{~mm}$; compressive strength $f_{\mathrm{c}}^{\prime}=23.8$ and $8.0 \mathrm{MPa}$ ). The very low concrete strength of 8.0 MPa was accidental due to an error at the mix plant by workers adding more water. However, the low-strength concrete and small cover to reinforcing bars can help assess the effect of poor-quality concrete and workmanship on crack initiation and propagation. Table 3 shows a description of the two series of specimens tested by Vu et al. (2005) (SI, SII) and the two new series of specimens (SIII, SIV). At completion of the tests, reinforcing bars were removed and cleaned, and the weight loss of bars was measured according to the gravimetric weight loss method as specified in ASTM G1-90 (ASTM, 1990).

Immediately after crack initiation, $10 \mathrm{~mm}$ linear potentiometer displacement transducers (POTs) were glued onto both sides of the crack. Up to three POTs were used for each steel bar except in specimens SIV-1 and SIV-2 whereas only two POTs were used for the edge bars. For all specimens a 'dummy' POT was used to

\begin{tabular}{lcccccc}
\hline Series & $\begin{array}{c}\text { Cement: } \\
\mathrm{kg} / \mathrm{m}^{3}\end{array}$ & $\begin{array}{c}\text { Fly ash: } \\
\mathrm{kg} / \mathrm{m}^{3}\end{array}$ & $\begin{array}{c}\text { Coarse aggregates: } \\
\mathrm{kg} / \mathrm{m}^{3}\end{array}$ & $\begin{array}{c}\text { Dune sand: } \\
\mathrm{kg} / \mathrm{m}^{3}\end{array}$ & $\begin{array}{c}\text { Coarse sand: } \\
\mathrm{kg} / \mathrm{m}^{3}\end{array}$ & $\begin{array}{c}\text { Water/binder } \\
\mathrm{ratio}\end{array}$ \\
\hline III & 262.5 & 68.75 & 1000 & 487.5 & 400 & 0.37 \\
IV & 208.0 & 50.00 & 1033 & 533.0 & 367 & 0.59
\end{tabular}

Table 2. Concrete mix data 


\begin{tabular}{|c|c|c|c|c|c|c|c|c|}
\hline Series & Specimen & $\mathrm{C}: \mathrm{mm}$ & $d: m m$ & $f_{c}^{\prime}: M P a$ & $f_{t, c y l}: M P a$ & $\begin{array}{l}i_{\text {corr(nom) }}: \\
\mu \mathrm{A} / \mathrm{cm}^{2}\end{array}$ & $\begin{array}{l}i_{\text {corr(exp): }} \\
\mu \mathrm{A} / \mathrm{cm}^{2}\end{array}$ & $t_{1 s t}+: h$ \\
\hline \multirow[t]{4}{*}{$\left.\right|^{*}$} & $\mid-1$ & 25 & 16 & $20 \cdot 0$ & 3.06 & 100 & $140 \cdot 3$ & $134 \cdot 0$ \\
\hline & $1-2$ & 50 & 16 & $20 \cdot 0$ & $3 \cdot 06$ & 100 & $128 \cdot 1$ & $194 \cdot 7$ \\
\hline & $1-3$ & 25 & 16 & $43 \cdot 0$ & $4 \cdot 16$ & 100 & $93 \cdot 2$ & $116 \cdot 0$ \\
\hline & $\mid-4$ & 50 & 16 & $43 \cdot 0$ & $4 \cdot 16$ & 100 & $106 \cdot 3$ & $155 \cdot 7$ \\
\hline \multirow[t]{4}{*}{$\|^{*}$} & $\|-1$ & 50 & 16 & $42 \cdot 25$ & 3.94 & 100 & $86 \cdot 8$ & $402 \cdot 8$ \\
\hline & $\|-2$ & 25 & 16 & $42 \cdot 25$ & 3.94 & 100 & $140 \cdot 3$ & $136 \cdot 1$ \\
\hline & $11-3$ & 50 & 16 & $52 \cdot 7$ & $4 \cdot 55$ & 100 & $123 \cdot 6$ & $490 \cdot 7$ \\
\hline & II-4 & 25 & 16 & $52 \cdot 7$ & $4 \cdot 55$ & 100 & $112 \cdot 7$ & $223 \cdot 1$ \\
\hline \multirow[t]{4}{*}{ III } & SIII-1 & 20 & 16 & $23 \cdot 4$ & $2 \cdot 40$ & 169 & $184 \cdot 0$ & $72 \cdot 0 \neq$ \\
\hline & SIII-2 & 10 & 16 & $23 \cdot 4$ & $2 \cdot 40$ & 100 & $172 \cdot 0$ & $36 \cdot 0 \neq$ \\
\hline & SIII-3 & 20 & 27 & $23 \cdot 4$ & $2 \cdot 40$ & 100 & $139 \cdot 0$ & $54 \cdot 0 \neq$ \\
\hline & SIII-4 & 10 & 27 & $23 \cdot 4$ & $2 \cdot 40$ & 59 & $116 \cdot 0$ & $46 \cdot 0 \neq$ \\
\hline \multirow[t]{2}{*}{ IV } & SIV-1 & 20 & 16 & $8 \cdot 0$ & $1 \cdot 30$ & 100 & $140 \cdot 0$ & $123 \cdot 0 \neq$ \\
\hline & SIV-2 & 10 & 16 & 8.0 & $1 \cdot 30$ & 100 & $153 \cdot 0$ & $69 \cdot 0 \neq$ \\
\hline
\end{tabular}

* From Vu et al. (2005)

$+t_{1 \text { st }}$ corrected for $i_{\text {corr }}=100 \mu \mathrm{A} / \mathrm{cm}^{2}$

₹ For exterior bars

Table 3. Test variables and time to crack initiation for each specimen.

correct POT measurements arising from temperature changes and long-term drifts in the electrical circuit.

\section{Results from accelerated corrosion testing}

\section{Crack initiation}

The first appearance of cracking (crack initiation) on the concrete surfaces was verified by frequent daily visual observations using a crack detection microscope with an accuracy of $0.02 \mathrm{~mm}$. At the end of the experiments (after $1860 \mathrm{~h}$ ), the maximum measured crack width ranged from $1.08 \mathrm{~mm}$ (SIV-1) to $2 \cdot 18 \mathrm{~mm}$ (SIII-2).

The calculated corrosion rates based on the gravimetric weight loss $\left(i_{\text {corr(exp) }}\right)$ of the bars were higher than the nominal corrosion rates $\left(i_{\text {corr(nom) }}\right)$ in almost all the slabs (see Table 3 ). Therefore, to enable meaningful comparisons between specimen results, times to crack initiation $\left(t_{1 \mathrm{st}}\right)$ and crack propagation $\left(t_{\mathrm{sp}}\right)$ were corrected to an identical corrosion rate of $100 \mu \mathrm{A} / \mathrm{cm}^{2}$ by multiplying the observed time by $i_{\text {corr(exp) }} / 100$ (e.g. if the measured corrosion rate is $140 \mu \mathrm{A} / \mathrm{cm}^{2}$ then the measured times to crack initiation and propagation are increased by a factor 140/100).

Times to crack initiation for a hairline crack of width $w=0.05 \mathrm{~mm}$ are shown in Table 3. Crack initiation in the current tests (series III and IV) started much earlier than that observed by Vu et al. (2005) (series I and II). This is mainly due to the lower covers in the later tests but also perhaps because series I and II crack initiation and propagation test data were only obtained from an average of all reinforcing bars in a specimen.

Table 3 and Figure 8 show that $t_{1 \text { st }}$ in all the specimens increases with increase in concrete cover. This is in agreement with the results found in all available research. It was also observed that $t_{1 \text { st }}$ decreases with increasing reinforcing bar diameter. This is also in agreement with observations mentioned by Rodriguez et al. (1996), Austroads (2004) and Alonso et al. (1998). However, other models (Bazant, 1979; Liu and Weyers, 1998; Morinaga,

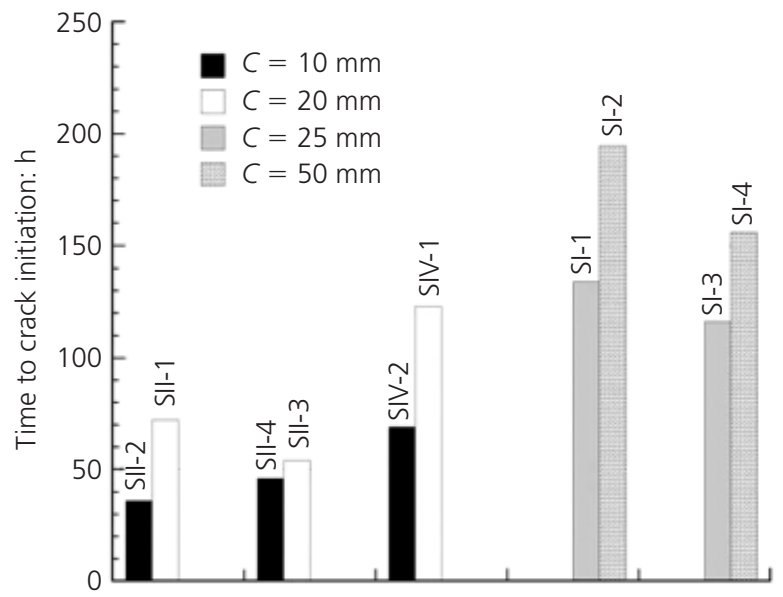

Figure 8. Effect of concrete cover on time to crack initiation 
1989) predict an increase in $t_{1 \mathrm{st}}$ with increasing reinforcing bar diameter.

Figure 9 shows that a significant increase in $t_{1 \text { st }}$ occurs for lower strength concrete for all SIV slabs and slabs SI-1 and SI-2. This can be attributed to the high porosity in low-strength concrete allowing for corrosion products to dissipate in the concrete pores before creating tensile pressure on the concrete cover. The effect of high concrete porosity (normally associated with low concrete compressive strength) in dissipating the corrosion product and therefore delaying crack initiation has also been observed in other accelerated corrosion tests using impressed currents (Rodriguez et al., 1996; Vu, 2003). Time to crack initiation is composed of two parts: the time to corrosion initiation and the time taken by the corrosion products to cause hairline cover cracking. For concrete structures exposed to chlorides from the environment, corrosion initiation will be faster in poor-quality concrete due to the ease of ingress of chlorides through the porous cover. Because in such cases the time to corrosion initiation is more dominant than the time for the corrosion products to crack the concrete cover, $t_{1 \mathrm{st}}$ will be smaller in low-strength concrete.

The effect of reinforcement confinement could not be observed for crack initiation as $t_{1 \text { st }}$ was very short and the first cracks for both exterior and interior bars were observed during the same visual inspection. Any differences in time would therefore not have been observed. This is clearly an area for further research: continual monitoring is needed to accurately record the times to crack initiation as affected by reinforcement confinement.

\section{Crack propagation}

Figures 10 and 11 show crack propagation in slabs SIII and SIV for exterior (bars 1 and 4 in Figure 6(b)) and interior (bars 2 and 3 in Figure 6(b)) reinforcing bars respectively. Figure 12 shows crack propagation for all series I and II specimens. As shown in these figures, it takes longer for cracks to propagate to the same

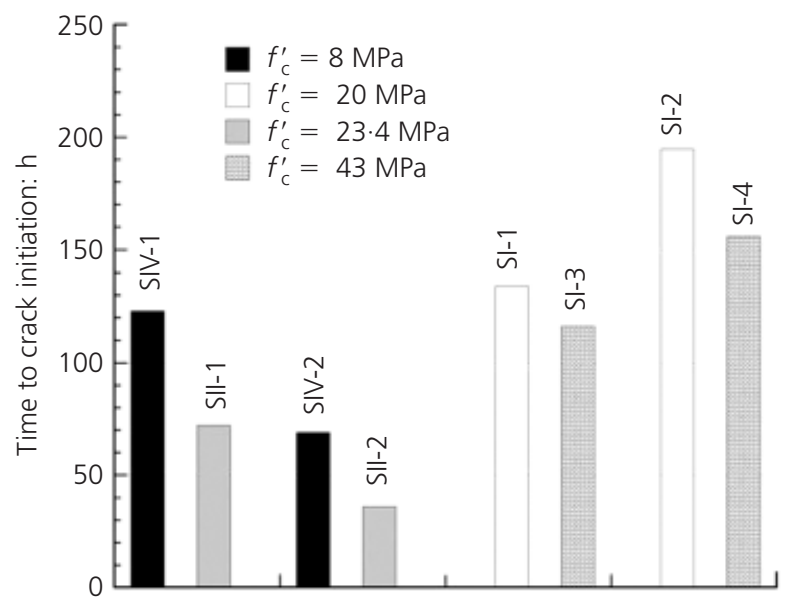

Figure 9. Effect of concrete compressive strength on time to crack initiation

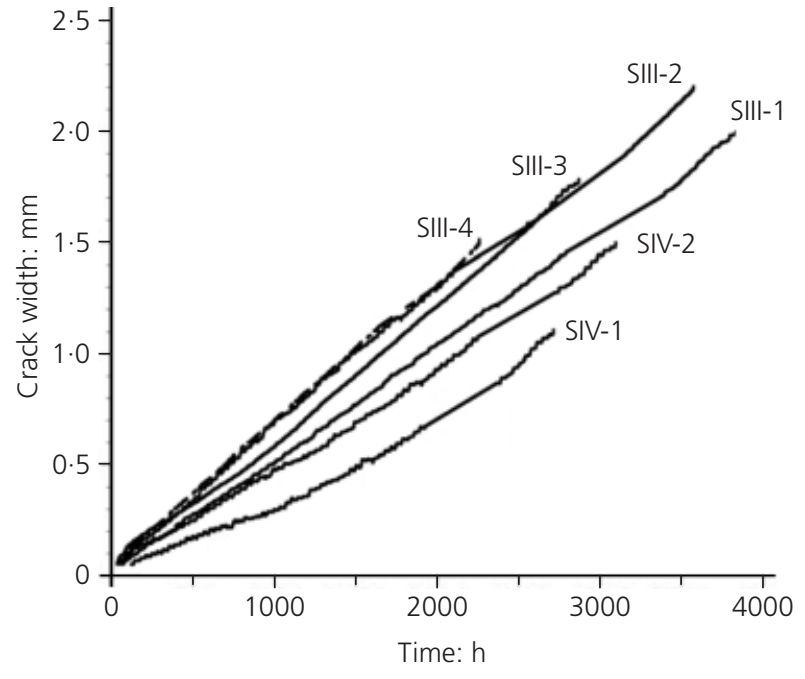

Figure 10. Crack propagation in series III and IV slabs (exterior reinforcing bars $i_{\text {corr }}=100 \mu \mathrm{A} / \mathrm{cm}^{2}$ )

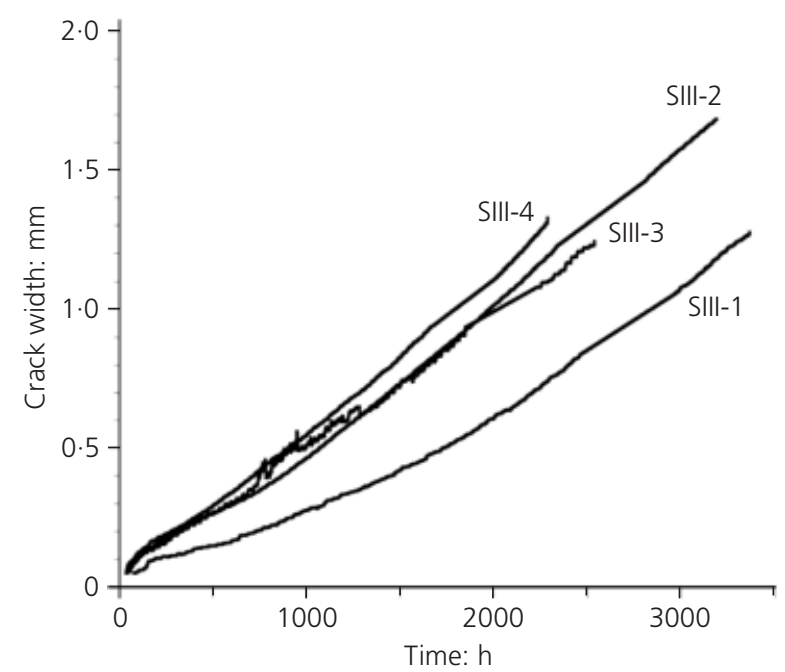

Figure 11. Crack propagation in series III slabs (interior reinforcing bars $i_{\text {corr }}=100 \mu \mathrm{A} / \mathrm{cm}^{2}$ ), for $f_{c}^{\prime}=23.4 \mathrm{MPa}$

level of crack width for specimens with a larger cover, smaller reinforcing bar diameter and lower concrete compressive strength (or higher $\mathrm{w} / \mathrm{c}$ ratio). The effect of high concrete porosity in delaying crack propagation was also observed in accelerated corrosion tests carried out by Alonso et al. (1998).

Figure 13 shows a comparison of crack propagation times for exterior and interior bars in specimens SIII-1 and SIII-3. Figure 14 shows the percentage increase in crack propagation times for interior reinforcing bars when compared with crack propagation times for exterior (edge) bars. As is evident from Figure 14, the times for crack propagation for interior reinforcing bars are 6$103 \%$ higher than those for exterior (edge) reinforcing bars. In 
Concrete cover cracking caused by steel

reinforcement corrosion

Al-Harthy, Stewart and Mullard

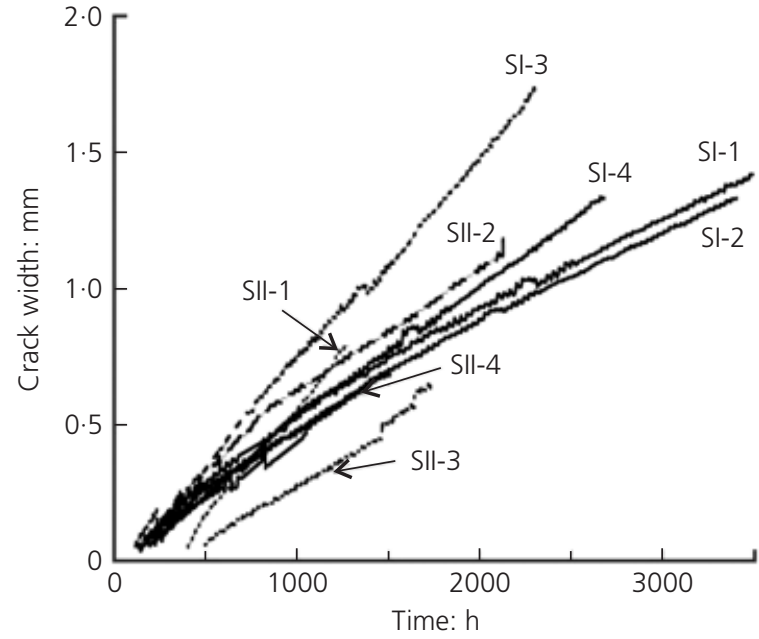

Figure 12. Crack propagation for series I and II $\left(i_{\text {corr }}=100\right.$ $\left.\mu \mathrm{A} / \mathrm{cm}^{2}\right)$

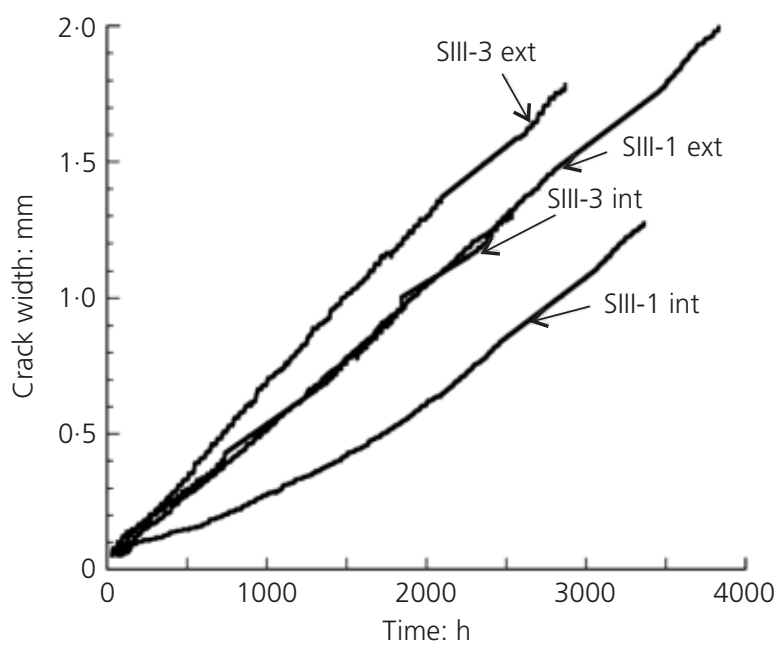

Figure 13. Crack propagation times for exterior bars and interior bars in SIII-1 and SIII-2

other words, the rate of crack propagation is $10-50 \%$ higher for reduced reinforcement confinement. For crack widths of 0.2 $1.2 \mathrm{~mm}$, the average increases in crack propagation times for interior reinforcing bars are $67,33,30$ and $26 \%$ for SIII-1, SIII-2, SIII-3 and SIII-4 respectively. Clearly, the degree of confinement of the reinforcing bars has a significant effect on crack propagation. This confinement effect will allow for reduced expansions and cracking over interior reinforcing bars when compared with corrosion-induced cracking above exterior reinforcing bars. While the influence of stirrups may influence the confinement effects reported here, there is clearly a need for further research into the effects of stirrups on confinement and crack propagation.

Figure 15 shows comparisons between experimental data on SIII-

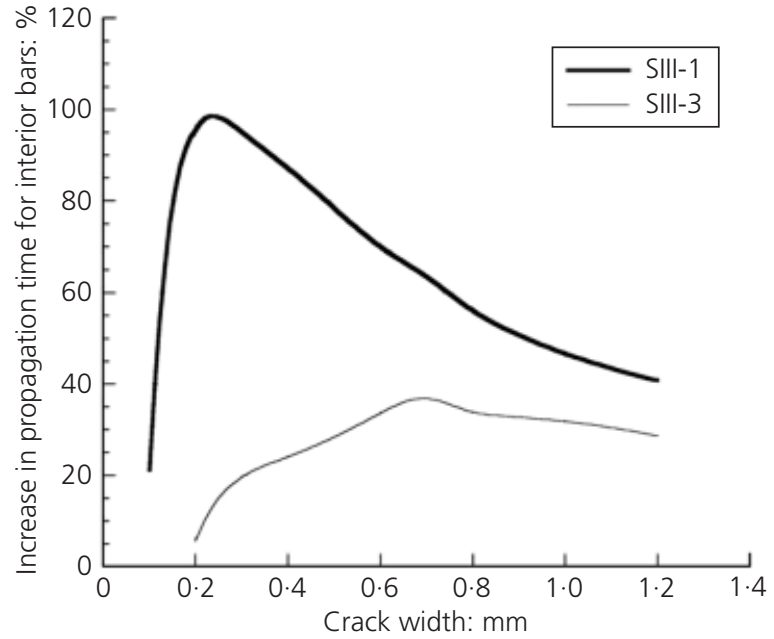

Figure 14. Percentage difference of propagation times between exterior bars and interior bars

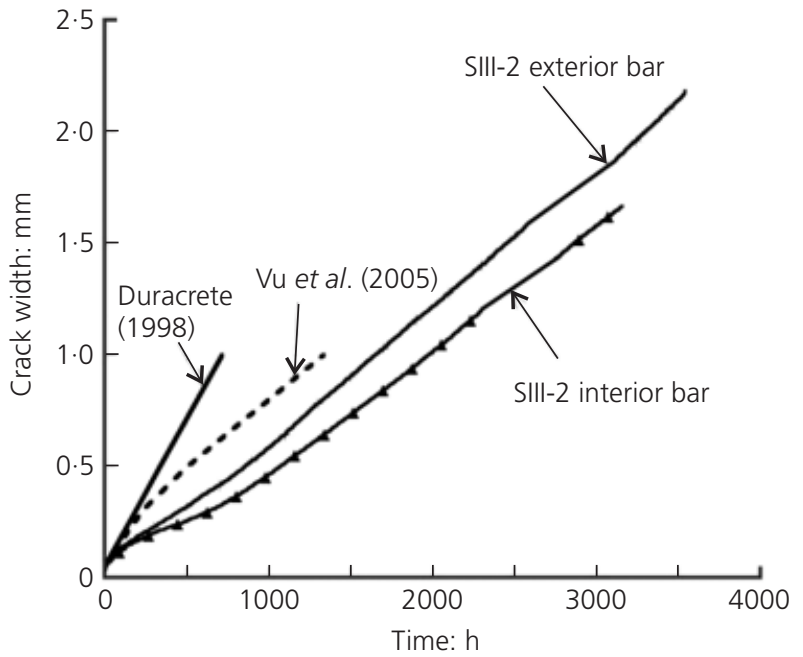

Figure 15. Comparison of experimental data with Vu et al. (2005) and Duracrete (1998) models for slab SIII-2

2 and the predictive models of $\mathrm{Vu}$ et al. (2005) and Duracrete (1998). The model of Vu et al. (2005) more closely reproduces the experimental trend, although at times quite conservatively. For these $24 \mathrm{MPa}$ specimens, the difference between the $\mathrm{Vu}$ et al. model prediction for a limit crack width of $1.0 \mathrm{~mm}$ and the experimental data is about $23 \%$. However, this difference is larger for the lower strength concrete (67\%). The Duracrete (1998) model gives the smallest propagation time to reach a given limit crack width. The advantage of the model of Vu et al. (2005) is that it can incorporate the rate of loading correction factor $\left(k_{\mathrm{R}}\right)$, but its accuracy depends on the accuracy of this factor. The Duracrete (1998) model was developed from testing singly reinforced prisms with corrosion rates ranging from 3 to $100 \mu \mathrm{A} /$ $\mathrm{cm}^{2}$, but does not incorporate a rate of loading correction factor 
and may therefore overpredict the propagation times for real corrosion rates (below $1 \mu \mathrm{A} / \mathrm{cm}^{2}$ ).

\section{Conclusions}

Crack initiation and propagation of RC slab specimens subjected to accelerated corrosion testing were investigated. It was found that time to crack initiation and crack propagation time increase with increasing concrete cover and with decreasing reinforcing bar diameter and concrete compressive strength. The experimental time to crack initiation was compared with nine predictive models. The predictive models were found to give widely scattered results and more data are needed in order to better assess the accuracy of the predictive models. The rate of crack propagation for exterior reinforcing bars was found to be 10 $50 \%$ higher than for interior reinforcing bars due to reduced reinforcement confinement to the exterior bars.

\section{Acknowledgements}

This research was conducted while the first author was on sabbatical at The University of Newcastle, Australia. The support provided by The University of Newcastle and the Australian Research Council is gratefully acknowledged.

\section{REFERENCES}

ACl (American Concrete Institute) (1978) Prediction of Creep, Shrinkage and Temperature Effects 2. ACI Committee 209, Detroit, MI.

Al-Harthy AS and Stewart MG (2006) A Review of Predictive Models for Cracking in Concrete due to Reinforcement Corrosion. Centre for Infrastructure Performance and Reliability, University of Newcastle, Research report No. 258.06.06.

Alonso C, Andrade C, Rodriguez J and Diez JM (1998) Factors controlling cracking of concrete affected by reinforcement corrosion. Materials and Structures 31(211): 435-441.

Andrade C, Alonso C and Molina FJ (1993) Cover cracking as a function of bar corrosion: Part I - experimental test. Materials and Structures 26(8): 453-464.

ASTM (ASTM International) (1990) ASTM G1-90: Standard practice for preparing, cleaning and evaluating corrosion test specimens. ASTM, West Conshohocken, PA.

Austroads (2004) Concrete Durability - Development of Models to Predict and Extend the Service Life of Concrete Bridges. Austroads, Sydney, Austrailia, Publication AP-R245/04, p. 137.

Bazant ZP (1979) Physical model for steel corrosion in concrete sea structures. Journal of the Structural Division ASCE 105(6): 1137-1153.

Bhargava K, Ghosh AK, Mori Y and Ramanujam S (2005) Modeling of time to corrosion-induced cover cracking in reinforced concrete structures. Cement \& Concrete Research 35(23): 2203-2218

Brite-EuRam (1995) The Residual Service Life of Reinforced Concrete Structures, Final Technical Report. Report No. BRUE-CT92-0591.
Care S and Raharinaivo A (2007) Influence of impressed current on the initiation of damage in reinforced mortar due to corrosion of embedded steel. Cement and Concrete Research 37(12): 1598-1612.

Chernin L and Val DV (2008) Prediction of cover cracking in reinforced concrete structures due to corrosion. Proceedings of the 1st International Conference on Construction Heritage in Coastal and Marine Environments: Damage, Diagnostic, Maintenance and Rehabilitation (MEDACHS'08), Lisbon. CD-Rom.

Duracrete (1998) Probabilistic Performance Based Durability Design of Concrete Structures, Modeling of Degradation. Duracrete, Gouda, the Netherlands, Document BE95-1347/ R4-5.

Duracrete (2000) Probabilistic Performance Based Durability Design of Concrete Structures, General Guidelines for Durability Design and Redesign. Duracrete, Gouda, the Netherlands, Document BE95-1347/R15.

Frangopol DM, Lin KY and Estes AC (1997) Life-cycle cost design of deteriorating structures. ASCE Journal of Structural Engineering 123(6): 523-528.

Koch GH, Brongers PH, Thomson NG, Virmani YP and Payer JH (2002) Corrosion Costs and Prevention Strategies in the United States. Federal Highway Administration, Washington, DC, Report No. FHWA-RD-010156.

Liang MT, Lin LH and Liang CH (2002) Service life prediction of existing reinforced concrete bridges exposed to chloride environment. ASCE Journal of Infrastructure Systems 8(3): $76-85$.

Liu Y and Weyers RE (1998) Modeling the time-to-corrosion cracking in chloride contaminated reinforced concrete structures. ACI Materials Journal 95(6): 675-681.

Molina FJ, Alonso C and Andrade C (1993) Cover cracking as a function of rebar corrosion: Part 2 - numerical model. Materials and Structures 26(9): 532-548.

Morinaga S (1989) Prediction of Service Life of Reinforced Concrete Buildings Based on Rate of Corrosion of Reinforced Steel. Special Report of the Institute of Technology, Skimiza Corporation, Japan.

Mullard JA and Stewart MG (2009) Stochastic assessment of the timing and efficiency of maintenance for corroding RC structures. Journal of Structural Engineering, ASCE 135(8): 887-895.

Pantazopoulou SJ and Papoulia KD (2001) Modeling cover cracking due to reinforcement corrosion in RC structures. ASCE Journal of Engineering Mechanics 127(4): 342-351.

Rasheeduzzafar H, Al-Saadoun SS and Al-Gahtani AS (1992) Corrosion cracking in relation to bar diameter, cover and concrete quality. ASCE Journal of Materials in Civil Engineering 4(4): 327-342.

Rodriguez J, Ortega LM, Casal J and Diez JM (1996) Corrosion of reinforcement and service life of concrete structures. In Durability of Building Materials and Components (Sjostrom C (ed.)). E \& FN Spon, London, pp. 117-126. 
Stewart MG (2006) Spatial variability of damage and expected maintenance costs for deteriorating RC structures. Structures and Infrastructure Engineering 2(2): 79-90.

Stewart MG and Val DV (2003) Multiple limit states and expected failure costs for deteriorating RC highway bridges. ASCE Journal of Bridge Engineering 8(6): 405-415.

Torres-Acosta AA, Fabela-Gallegos MJ, Munoz-Noval A, VasquezVega D and Hernandez-Jimenez JR (2004) Influence of corrosion on the structural stiffness of reinforced beams. Corrosion 60(9): 862-872.

Vidal T, Castel A and Francois R (2004) Analyzing crack width to predict corrosion in reinforced concrete. Cement and Concrete Research 34(1): 165-174.

Vu KAT (2003) Corrosion Induced Cracking and Spatial Time Dependent Reliability Analysis of Reinforced Concrete
Structures. PhD thesis, University of Newcastle, NSW.

Vu K and Stewart MG (2000) Structural reliability of concrete bridges including improved chloride-induced models. Structural Safety 22(4): 313-333.

Vu K, Stewart MG and Mullard J (2005) Corrosion-induced cracking: experimental data and predictive models. $A C I$ Structural Journal 102(5): 719-726.

Webster MP and Clark LA (2000) The structural effect of corrosion - an overview of the mechanism. Proceedings of Concrete Communication, Birmingham. BCA, Camberley, pp. 409-421.

Zhang R, Castel A and Francois R (2010) Concrete cover cracking with reinforcement corrosion of RC beams during chlorideinduced corrosion process. Cement and Concrete Research 40(3): 415-425.

\section{WHAT DO YOU THINK?}

To discuss this paper, please submit up to 500 words to the editor at www.editorialmanager.com/macr by 1 March 2012. Your contribution will be forwarded to the author(s) for a reply and, if considered appropriate by the editorial panel, will be published as a discussion in a future issue of the journal. 